The bodily excess of a worldview: beyond a theoretical account of the world.

Pieter Meurs

pmeurs@vub.ac.be

\title{
Introduction
}

The world is changing rapidly. New evolutions in communication technology and changes in sociopolitical structures generate a spatio-temporal shift in our everyday experience of reality. We are living in a globalized world, in which the local is no longer something that exists in itself. The media confront us with the other side of the world. This 'other side of the world' can be considered literally as well as figuratively here: one the one hand, we get acquainted with parts and people of the world we never knew they existed. On the other, we're bound to learn that there is more to life than our own singular experience and reality. Our view on the world becomes evermore multilayered and complex. However at the same time, in our discovery of new worlds, we experience a loss of touch with things that are self-evident and nearby. A lot of people have the impression that their world lost its ever surveyable structure. The local world and its global counterpart seem to be difficult to harmonise. Life becomes fragmented, with times alienating even. Contemporary society engenders complex and controversial contradictions as a consequence of the schism between the experience of a rapidly changing world and the incapability or the lack of an appropriate view of that world.

As such, we should encourage the efforts towards a global thought of the world as an "attempt to develop world views that take into account as much as possible all aspects of our experience" (Aerts et al., 2007, p. 9). As a symbolic system a worldview can allow us to understand reality. It is a frame of reference, a system of meaning that deals with deep questions relating to our present, past and future existence. A worldview offers the possibility to understand and tackle the problems of everyday as well as scientific life. Many of us (and particularly in the West) interpret this understanding and tackling as a rather theoretical affair. A worldview offers a theoretical frame of reference by means of which reality can be explained and understood. One way or another it fulfils a need similar to the way mythological stories once did. Granted, the time of gods and supernatural heroes as in the poems of Homer is long gone, but that doesn't mean however there are still various narratives that make it possible to experience, explain and validate a certain 
way of life. It is a way of dealing with society, its a technology. The question then arises, what is understood within the confines of our contemporary worldview. Or in other words, how is our modern worldview conceived?

When we try to envisage an image of the world, this is mostly something framed within the concepts of our mind. A worldview refers to a rather theoretical and abstract account of how to understand life. This comes as no surprise, since the view or knowledge of the world we have mostly stems from books or informational media. We believe most of our knowledge of the world is theoretical. Our corporal perception, our bodily feelings are too personal and singular to gather an abstract and objective image of the world. When thinking of the world, it is the image of a map of the world in an atlas that comes to mind rather than the feel of the soil under our feet. As such, our modern worldview is something like a map, a more or less objective conception of how things are to be understood. Our understanding of reality foremost refers to a theoretical account. And this breaks down in a double approach of reality. On the one hand, it is our mind that is the legitimation for a worldview. The view refers to certain kind of rational knowledge. Reality has to work, it has to correspond with our logic. We try to frame the world within a rational way of thinking. On the other hand, the body of our perception rather refers to an idea, a mental image of the object. As such, our knowledge of the world, our worldview rather generates a theoretical and immaterial reality, a reality wherein the real body is of secondary importance. The body or tangible reality is nothing other than an instrument or a technology that offers the means to gain knowledge. In other words, it is by means of the body that the mind can get a clear idea of reality.

In this article, we don't want to dispute the possibility of the mind to get an understanding of reality. However, we do wonder why the body remains not only secondary and inferior to the mind in this sense, but also is simply at the disposal of it, as an instrument. Agreed, understanding and cognitive capabilities are in general linked to the confines of the mind and it is broadly accepted the body doesn't offer the possibility of objectively grasping reality. In these assumptions, the body is mostly related to subjective emotions, drifts and instincts. It refers to a brute and uncontrollable force that doesn't behave according to a rational logic. While in this article we don't want to argue the opposite of these arguments, we do believe there is something to say about the ability of our body to encounter the world. In this sense, one could easily refer to examples of everyday life that don't address immediately our cognitive knowledge. Doesn't our body know how to climb the stairs? Doesn't it know how to ride a bike? Doesn't it do these things 
without thinking, as an automatism? When we enter a room, we do have an immediate and precognitive understanding about our orientation in this room. There are so much things we know about the world without us being immediately conscious about it, without even having the slightest theoretical knowledge about it. As such, isn't it so the body also knows its way around in the world?

One could argue that these abilities simply refer to cerebral activity in our head, but then again, is the actual act of these actions not interwoven with every part and vein of our body? Furthermore, on its own, a brain doesn't ride a bike or climb the stairs. As such, isn't it short-sighted to simply reduce our abilities and view of the world to that complex organ in our heads? Or in other words: why would we assume our knowledge and view of the world simply refers to the mind as the agent of a rational and objective logic? The point here then, is the conviction that knowledge or a worldview cannot be merely confined to the realm of theory and abstract rationalism. The way we encounter or view the world exceeds theories and textbooks. It goes beyond abstract and objective data. In this sense, we believe that an analysis of our relation to the body can also teach us something about the assumed objectivity of our knowledge and view of the world. Moreover, it can help us to consider our worldview as a dynamic encounter, rather than as a static view in which everything has to be objective and follow a rational logic. As an aspect of a worldview, a critical focus on the body can mediate our naïve and all too theoretical distinction between subject and object. As a consequence, for the purpose of this paper, we will investigate how it was possible our concept of knowledge and our worldview foremost refers to an ability of the mind and why our body has become inferior to it. Furthermore, we will excavate what it is we loose when we don't take the body in account in a concept of a worldview.

\section{The decline of the body}

The growing importance of the mind as the foundation of existence together with the instrumentalization of the body has been described meticulously by Michel Foucault (2001). In his Discipline and Punish: the Birth of the Prison, he gives a very detailed account of how the object or the body turns into a mere instrument within the judiciary system. His analysis isn't confined to the judiciary system however. The subtitle of the work, the Birth of the Prison, not only refers to the origination of the prison system, but has a more subtle meaning as well: Foucault describes how the mind gradually functions more and more as a prison for the body. 
Foucault kicks off with a description of the death sentence of a man called Damiens in 1757. Guilty of patricide the sinner had to be purified by torture followed by death. Foucault records very meticulously how the immense painful corporal punishment of Damiens is exercised. With the same keen eye for detail, Foucault continues with a description of the daily timetable in a home for young criminals in Paris. Both punishments are different, but each characterize a certain style of punishment. By means of an investigation in punishment, Discipline and Punish elaborates the way in which modern society disciplines and normalizes. According to Foucault, corporal punishment starts to disappear in judiciary practice at the end of the 18th century. From then on, prisons as known today gradually became commonplace. The body no longer is the primary focus of criminal repression: "the body wasn't to be harmed, or at least as little as possible and only to affect something other than the body itself" (Foucault, 2001, p. 20, my translation). Foucault doesn't deny imprisonment or penalty concerns corporeality, but he indicates the immediate relation between body and punishment can no longer be compared with that of corporal punishment. The body rather becomes a technology, a medium. Corporal pain is no longer the most important part of punishment. This means a shift from the art of unbearable pains to an economy of suspended rights. This evolution towards a more humane way of punishment implies a change in the subject of the judiciary procedure: whereas punishment used to be aimed at the body, it now becomes evermore focussed on the mind. A punishment has to affect "heart, thought, will and spirit" (Idem, p. 28). According to Foucault, this evolution is a crucial moment in (criminal) history. The judiciary apparatus no longer has to focus on a tangible reality, but on a reality without a body.

This evolution meant the end of the lugubrious feast of punishment (the abolition of the public pillory counts as a good example). As a consequence, the executioner becomes systematically relieved by an army of technical specialists. A judge is assisted by doctors, clergymen, psychiatrists and pedagogues. Punishment isn't completely unrelated to physical pain and implies up to a certain sense an element of corporal punishment, but only as a consequence of a domination of immaterial punishment. In modern society, the body first and foremost becomes something with utility value, an implement. The mastery or controllability of the body gains importance. (This is also well reflected in the contemporary relation with the body. Our bodies are not simply modelled and trained in such a way to be as handsome and strong as possible, but have to function without problems and experience pleasure on command). 


\section{The birth of the modern mind}

In Discipline and Punish Foucault describes how the modern society becomes gradually more focussed on the mind and how the body gets enclosed within positions of power. Foucault speaks about a political technology of the body to address the fact that the body is encased within a political field which enables the possibility of control. This political field is linked with a technical utility value. It implies the subjection of the body to a certain power. The specificity of this power should be understood as a network of tense relations of certain dispositions, tactics and techniques that penetrate society in a fundamental way. In this sense, power is not inasmuch related to a central authority or position, but is decentralized and related to dispositions and dynamics. As such, power produces authority and vice versa. Foucault describes these authorities by means of discourses of knowledge. According to him, relations of power are always already bound to specific fields of knowledge. These 'knowledge-power' relations generate the specific power and knowledge at the same time. As such, power and knowledge are effects of their own relation and don't exist an sich. Thus, power is knowledge and knowledge is power. When Foucault speaks about the mastery over the body, he considers the political, judiciary, ... system as a whole of material elements and techniques that serve at once as a resource and an effect for the power-knowledge relation. According to Foucault, and this is important here, it is the modern conception of the mind that brings together the effects of a specific power with a specific knowledge. It is our contemporary worldview that generates a specific knowledge and authority.

The victim of this power appears to be the body. In the course of history, Foucault recognizes a instrumental focus on the body: "the body that is manipulated, trained, modelled; this body that obeys, reacts and becomes more powerful and agile" (Idem, p. 189). He considers a discourse that ranges from a metaphysical over a political to a techno-scientifical register as the ground of an evolution that conceive the body as an instrument that is controllable. This discourse largely goes back to evolutions in historical Western discourse. Today, however, it cannot be simply confined to such a Western heritage. In the process of globalization, cultural contexts beyond the EuroAmerican intertwine with this discourse. Our worldview can not easily be understood as a "local phenomenon" nowadays as its applications have made possible an increased interconnection between different places on the globe. In turn, the increasing accessibility of different worldviews from all over the world has strongly influenced our inspirations, choices and perspectives. However, some of the fundamental baselines of the historical Western discourse still run through our contemporary encounter with the world. They are still at play in the modern power- 
knowledge relation. Influenced by the Enlightenment discourse and perpetuated by the dawn of the scientific era in the $17^{\text {th }}$ century and its still lasting contemporary importance, rationality and certainty have become important dispositions. They have become the main epistemological ground for knowledge. They form the pretext for our contemporary way of thinking the world and ourselves. In order to understand or explain reality, we refer to an authority that follows a rational logic. This crucial idea of the Enlightenment is grasped within the concepts of subjectivity, understood as a kind of individualism and autonomy. Together, this leads to the central place of the subject in this discourse, to be understood as the potential to grasp the objectivity of one's own actions. Although often criticized and challenged by non-Western traditions (oriental philosophy for example), our contemporary view of the world can be described by means of a division of subject and object, of mind and body. This play between subject and object can be traced back to the philosophy of Descartes and fits within his epistemological endeavour for certainty and univocality.

Descartes tried to break with the prevailing philosophical traditions. Together with contemporaries as Galileo and Bacon among others, he wanted to free mankind from the naive traditions of irrationality and from man's self-incurred immaturity'. It fitted in a broader Zeitgeist that slowly pushed aside the up till then predominant theological explanations and concepts in favour of scientific knowledge. Descartes hoped to penetrate the core of human life and the world. Therefore, as a mode of inquiry, he doubted everything save what he thought could not be doubted: clear and distinct ideas. His radical doubt made Descartes sceptical: a scientific account of reality can't be led and be tempted by mere sensory perception and its delusive phenomena. Persisting in his radical doubt, Descartes had convinced himself that there is absolutely nothing in the world to be certain of: everything could be an illusion. Thinking however had to be something different. Even if I could think everything is an illusion, I still have to admit this I has to be something. Hence there seems to be one thing there can be no doubt about: I exists. Descartes made the I the one steady argument and his basic foundation of knowledge and philosophy. The existence of the I is derived from the fact that I think and therefore only exists when I thinks. This "I think therefore I am" marks the birth of the Cartesian Cogito. The Cogito is clear and distinct and thus the only way to penetrate true reality. In the form of transcendent knowledge, it entails the subjectivity praised by the Enlightenment. The conscious and thinking subject refers to the possibility of an objective epistemology. It offers certainty. This objective knowledge is engendered within a rational mode of thinking. Objectivity has nothing to do with emotions, 
feelings or the sensing body. As such, the result of Descartes' critical investigation culminated in the radical dualism of mind and body, that already had been proposed by Plato and Christian philosophy. The Cartesian system offers two parallel, but independent worlds: one of the mind and one of the body, or one of the subject and one of the object. Cartesian dualism became a stronghold in Western thinking and got endorsed by a mode of thinking that became evermore important in which the subject or mind is the basic foundation for existential and epistemological needs. It carries the possibility to engender a set of meaning and symbols that is the factual pretext for a certain technology of power over a body.

Foucault's political history or of the body means nothing other than a genealogy of the modern mind. By investigating the transformation of the way in which the body is enclosed within powerrelations changed over time, Foucault has not only marked the presence of the modern mind, but also its technology. It considers the body as an instrument, a means to control. The body more or less gets imprisoned within the confines of the mind. It is the mind that becomes the primary way to approach reality. This has everything to do with the presumption of one the one hand the possibility of the mind to reach rational and certain representations and a clear insight in subject and objects and on the other hand the impossibility of the emotional body to offer clear and distinct ideas.

\section{Towards a corporal worldview?}

Thus far we have argued that our worldview is captured within a certain discourse or powerdisposition and that as a consequence of this, not only the body becomes reduced to an instrument, but the primary way to encounter is through the mind. The body is something that is merely a means, the body does not have a meaning or purpose in itself. At the same time however, since our mind is the most important agent, this allows our view of the world to be clear and rational. Even more, the endeavour to have objective ideas about reality engenders the possibility of control and mastery. It seems this logic has led to a discourse on the make-ability of man and world, and on transcendence through critical investigation of body and world. At first glance then, this evolution should be encouraged, as it at least carries the promise of the possibility of creating a better life. However, as already mentioned in the beginning of this text, people still experience the feeling of alienation. This existential malaise is a consequence of the experience that the creation of better life isn't successful. In other words, the ideal of make-ability, control and objectivity fails. Reality seems to be more than simply rational. This feeling of 
existential discordance finds its ground in the relation between the lack of an appropriate worldview and an all too rapidly changing world. More concrete this means a worldview can not be confined within the limits of the objective, the rational and the theoretical. As such, in so far as a worldview is a theoretical account that makes it possible to understand reality, it always already has to exceed itself and go beyond its strictly theoretical order.

And this is were the body as an encounter with the world kicks in. The body cannot be confined within a theoretical or rational order. It always already does or is, without us being conscious or rationally knowing about is. The French philosopher Maurice Merleau-Ponty was one of the first to grasp this important significance of our bodily existence. As a phenomenologist he was intrigued by the Lebenswelt or life-world as described by his master Edmund Husserl. Merleau-Ponty's philosophy is a reaction against the classical discourse on the subject and the object. When writing his magnum opus La Phénoménology de la Perception (1945), this discourse was represented by two prevailing but contradicting and insufficient worldviews: empiricism and intellectualism. The first refers to the study about objects and causal relations, the latter starts from an autonomous mind that constructs reality. Both felt very strongly about the already mentioned rationality and objectivity as an epistemological ground. According to Merleau-Ponty empiricism nor intellectualism succeeds in thinking our being in the world because of a respectively too weak and too strong concept of the mind. This antithesis might have been specific for that time but is still an important discussion today. It questions the ground and legitimation of a specific worldview: do we take the objects around us for granted and do we let them speak for themselves or do we encounter the world starting from an mental image of the world? Merleau-Ponty shows us a possibility that exceeds both opposite points of view and neutralizes their contradiction. The body will be of crucial importance in his analysis.

From a critique on the prejudices of the two prevailing discourses, Merleau-Ponty opens an investigation in our primary encounter with the world. In questioning our being in the world, he considers perception as the most crucial thing. Through a fundamental analysis of perception, he describes the body as the vehicle of our being in the world (le véhicule de l'être). It is the body that is crucial in our encounter with the world. It is the embodiment of perception. Perception is our originary relation with the world but is not an act of the mind, it completes itself on a preconscious level. Here, we already encounter the world, without having a theoretical understanding about it. The body and the world are already there before theory or the mind can make a 
reflection on them. As such, "the world is not that what I think, but that what I live" (Idem., p. XII, my translation). The body is nothing other than our embodiment of an originary relation with reality by which we have direct access to the world. What is important here, is the understanding that this originary relation precedes every reflection and as such can not offer us the world as a theoretical or objective whole. The body always already is there (déjà-là). Dillon has thoroughly grasped Merleau-Ponty's primacy of perception: "if perception is primary, it is not something a subject does: perception is no longer to be conceived as the activity of a soul substance, nor as an accident that it passively sustains. Perception is not something I do or something that happens to me - because the $I$ is a product of reflection and perception is older, more primordial than reflection. Perception is thus prepersonal" (1988, p. 55). This prepersonal perception, our direct access to the world, remains athetical as it is pre-reflexive: there is no clear definition or determination of the world. This phenomenal field of perception is unclear. It is fundamentally ambiguous. Maybe this is the most important aspects of Merleau-Ponty philosophy of the body: our first encounter with the world is not characterized by clear and distinct concepts. There is no objective truth on this level. Ambiguity refers to an non-transparent twilight zone inherent within the field of perception. This means our encounter with the world is not characterized by objectivity, univocality or certainty. It is in this sense, Merleau-Ponty's philosophy of our bodily being in the world is a fundamental critique towards our traditional Western thought: the assumption of a simple and distinct idea of the world is not able to think our embodied being in the world. With Merleau-Ponty, the body stands for the opposite of an objective view of the world. It is nothing other than the raw and atheoretical presence of the practical. In this sense, we don't have a body, but are a body.

This means the view of the world doesn't simply refer to an intelligible or conscious theory, but emerges out of the embodied being in the world. Not mere theoretical understanding is the basis for a worldview since the body is always already at grips with a world. In other words, our worldview is not without a context. The ambiguity and the pre-reflexivity - in short: MerleauPonty's corporeality - are not the objects to be analysed or revealed, but merely give the context for the way in which the world is viewed. Crucial in his philosophy is the idea that we find ourselves always already within a pre-conscious, corporal point of view and therefore we're not able to protrude to an epistemological certainty or objectivity. Merleau-Ponty speaks of "a vigilance that doesn't let us forget the ground of all knowing" (1960, p. 138, my translation). This might be a correct description of the ambiguity that indicates the flaws and deficiencies inherent 
to all views of the world. This means Merleau-Ponty suppresses the Cartesian distinction between body and mind. According to Merleau-Ponty, both are inseparable: as long as we consider the body as an object, it simply functions as an instrument; and as long as we consider the mind as a subject, it will only know objects that are clear and distinct. We no longer have a body, but are a body. In this sense, a worldview is nothing more than a view that always already is embodied in the world. It is not a concept located in an interior space we call the mind and it is not objective or simply theoretical. As such, a worldview can not simply refer to a theoretical account.

If, together with Merleau-Ponty, we consider the body as our primary entrance to reality, we have the perfect antidote for a worldview that focusses too much on a distinction between body and mind. From this follows on the one hand that the mind is not a reality without a body. Objects are not distinct or abstract things in themselves, but make up the realization (reality) of things. They are reality in their embodiment, not as a mental image. The real is embodied and not simply something that happens in the mind. On the other hand, the mind is not primary to the body. The body (and other 'objects' such as the world) is not simply an instrument to be controlled and mastered. It is the expression of existence. It makes it possible to explore the world, to gain knowledge that exceeds every theoretical account. At the least it does give us an account of our emotions and experiences, even if they are not that clear themselves. Reality can be ambiguous and does not necessary follow a rational logic.

Furthermore, this corporeality is a very important aspect for the generation of a worldview. It teaches us something about the way we view the world: this view is not simply theoretical, but is lived, experienced, embodied. It is not some abstract theory about reality, but is situated within a specific world. It literally and figuratively is in practice. It means that our worldview is not simply an objective and abstract view of the world, but a practice of the world: in viewing the world, we make the world visible, we make the world present: we make reality real. As such, in a corporal worldview, the world does not simply remain a world of theory, but is always already a practice itself as well. This means our body and the world can not be reduced to an instrument, since as existential elements they always already make up reality. Corporeality reveals existence as the connection of body and mind, of world and man, of people among themselves.

As such, a worldview does not escape its own being in the world. It means we always already are and find ourselves within a worldview, even if it is not made explicit as such. When we want to 
construct a worldview, we always encounter the inherent ambiguity. Determining or demarcating a worldview by means of objective or mere rational arguments is no longer possible. A worldview can not be closed, but will remain open at all times. Because of the fact we can not be completely certain or clear about things, this opens the possibility for other views, other ways, or in general: otherness. First and foremost this means there always is an opening and a possibility. A corporal worldview shows us our encounter with the world as a possibility to explore. This exploration isn't confined to a static map or to fundamental conditions, but is dynamic as it moves along and can show us things differently. As such, a worldview can be adapted and made appropriate in accordance with the needs.

\section{Concluding beyond the worldview}

Merleau-Ponty's philosophy can be considered as a critique as well as a major contribution to the Western worldview. His emphasis on the body as the pivot of our being in the world has put the belief in the omnipotent power of the mind into question. Our historical Western tradition failed to think this appropriately by reducing the body to a mere instrument. This is why we should be attentive to integrate the ability of the body to encounter the world when thinking about a concept as a worldview. It adds an opening to our worldview for reality always already escapes or exceeds the rational and the theoretical. It tempts the limits of our worldview in a fundamental way and excavates how our mode of thinking and encounter with the world falls short. At the same time however, we should be attentive not to have corporeality become trapped within the confines of a theory. When Merleau-Ponty considers the body as our primary entrance to the world, one could argue that there is a hint of essentializing the body or corporal existence. In contrast with the classical Western tradition, the order of mind and body could be overturned in favour of the body. In this sense, we should continue to consider both, mind and body on a same level. Just as the mind is an entrance to reality, the body is too. However, one would be wrong to consider them as two distinct or separate ways. Just as Merleau-Ponty argued: they are not separable. In that sense, rather than opposing the theoretical and the practical, the mind and the body, we should investigate in what way it is possible to diminish the borderline between the two. This would mean a fundamental investigation in the relation between subject and object. But maybe our words and definitions, our own worldview, don't allow this yet. Maybe, we still are too much bound to these concepts and aren't able to think 'outside the box'. The important thing here to bear in mind (or body), is that both aspects mutually exceed each other. The mind goes beyond the body and body goes beyond the mind. For a worldview, this can only mean that it always 
already limits itself to its own confines. These confines are not given by its ground, be that the ground of the mind or that of the body, but by reality or its realization itself. As such, a the world always already exceeds a view of that world (Nancy, 2002). We should try to think this excess for this is what allows the possible to become the real. 
Biblio

Foucault, M. 1982. The subject and power. In: Dreyfus, H. L. en Rabinow, P. 1982, Michel Foucault. Beyond structuralism and hermeneutics. Harvester Wheatsheaf, London.

Foucault, M. 2001. Discipline, toezicht en straf. De geboorte van de gevangenis. Historische Uitgeverij, Groningen.

Dillon, M. 1988. Merleau-Ponty's Ontology. Indiana University Press, Bloomington.

Merleau-Ponty, M. 1945. La phénoménologie de la perception. Paris, Gallimard.

Merleau-Ponty, M. 1960. Signes. Paris, Gallimard.

Nancy, J.-L. 2002. La création du monde ou la mondialisation. Paris, Gallimard.

It was Kant that blamed man for his immaturity with his Enlightenment-creed Sapere aude. Although Kant criticized Descartes for his epistemology, both can be presented as prominent thinkers of the Enlightenment. 